\title{
Study on Contra-Rotating Small-Sized Axial Flow Hydro Turbine
}

\author{
Ryosuke Sonohata $^{1}$, Junichiro Fukutomi ${ }^{2}$, Toru Shigemitsu ${ }^{2}$ \\ ${ }^{1}$ Graduate School of Advanced Technology and Science, The University of Tokushima, Tokushima, Japan \\ ${ }^{2}$ Institute of Technology and Science, The University of Tokushima, Tokushima, Japan \\ Email: t-shige@tokushima-u.ac.jp
}

Received September 24, 2012; revised November 6, 2012; accepted November 15, 2012

\begin{abstract}
It is thought that small hydropower generation is alternative energy, and the energy potential of small hydropower is large. The efficiency of small hydro turbines is lower than that of large one, and these small hydro turbine's common problems are out of operation by foreign materials. Then, there are demands for small hydro turbines to keep high performance and wide flow passage. Therefore, we adopted contra-rotating rotors which can be expected to achieve high performance and low-solidity rotors with wide flow passage in order to accomplish high performance and stable operation. Final goal on this study is development of an electric appliance type small hydro turbine which has high portability and makes an effective use of the unused small hydro power energy source. In the present paper, the performance and the internal flow conditions in detail of contra-rotating small-sized axial flow hydro turbine are shown as a first step of the research with the numerical flow analysis. Then, a capability adopting contra-rotating rotors to an electric appliance type small hydro turbine was discussed. Furthermore, the high performance design for it was considered by the numerical analysis results.
\end{abstract}

Keywords: Small-Sized Axial Turbine; Contra-Rotating Rotor; Electric Appliance; Renewable Energy; Internal Flow

\section{Introduction}

There is a strong demand to change energy resources of fossil fuels into renewable energy such as hydropower, wind power, solar energy and so on. Small hydropower generation is alternative energy, and the energy potential of small hydropower is large. Small hydropower facilities that generate about $1000 \mathrm{~kW}-100 \mathrm{~kW}$ have spread widely. However, it causes environmental destructions by a foundation construction and an installation of a draft tube. On the other hand, there are a lot of places that can generate about $1 \mathrm{~kW}-100 \mathrm{~W}$ (pico-hydropower) in agricultural water and a small stream. The small hydropower is expected to low environmental destructions. Therefore, darrieus and gyro-type turbines which are suitable for specifications of low head in agricultural water and a small river, were investigated and the performance characteristics and the optimum design parameter were discussed $[1,2]$. The internal flow of a spiral water turbine with wide flow passage and low-influence on environment was investigated [3]. Further, small-cross flow turbine using small stream as environmentally friendly picohydro turbine and savonius turbine with low cost were suggested, and the effects of performance improvement by installation and optimum position of shield plate were clarified [4-6]. The efficiency of small hydro turbines are lower than that of the large one, and these small hydro turbine's common problems are out of operation by foreign materials [7]. Then, there are demands for small hydro turbines to keep high performance and wide flow passage. Therefore, we adopted contra-rotating rotors which could be expected to achieve high performance and low-solidity rotors with wide flow passage in order to accomplish high performance and stable operation. In this study, significant compact hydro turbine is named small hydro turbine. Final goal on this study is development of an electric appliance type small hydro turbine which has high portability and makes an effective use of the unused small hydro power energy source.

In this research, we selected some places in Tokushima Prefecture in Japan, where a small hydropower can be generated, and conducted field tests of head, flow rate, water quality and capacity utilization. Then, it was found that it was necessary to develop a small hydro turbine that can generate electricity in wide flow rates range because change of flow rates in pico-hydro power was large. As a first step of this research a three dimensional steady numerical flow analysis was conducted with the commercial code (ANSYS-CFX) to investigate the internal flow condition in detail. 
In the present paper, the performance and the internal flow conditions in detail of contra-rotating small-sized axial flow hydro turbine are shown as a first step of the research with the numerical flow analysis. Then, a capability adopting contra-rotating rotors to an electric appliance type small hydro turbine was discussed. Furthermore, the high performance design for it was considered by the numerical analysis results.

\section{Rotor Design Method and Design Parameters}

Test turbine was assumed to install in a pipe of agricultural water with diameter of about 2 inch and a smallscale water-supply system. The designed flow rate and head was $Q_{\mathrm{d}}=0.0102 \mathrm{~m}^{3} / \mathrm{s}$ and $H_{\mathrm{d}}=4 \mathrm{~m}$ respectively based on the power $(P=100 \mathrm{~W})$, head $(H=4 \mathrm{~m})$, flow rate $\left(Q=0.01 \mathrm{~m}^{3} / \mathrm{s}\right)$ assumed in a pipe of agricultural water with diameter of about 2 inch and a small-scale water-supply system. The rotational speed of each front and rear rotor of the test turbine was $N_{\mathrm{f}}=N_{\mathrm{r}}=2600$ $\mathrm{min}^{-1}$ in order to consider a characteristic of a small generator which can produce about $100 \mathrm{~W}$. The rotor and the primary dimensions of a contra-rotating small-sized axial flow hydro turbine are shown in Figure 1 and Table 1 respectively. Casing diameter is $66 \mathrm{~mm}$ because tip clearance is $1 \mathrm{~mm}$, and the hub tip ratio of the front and rear rotors were $D_{\mathrm{hf}} / D_{\mathrm{tf}}=D_{\mathrm{hr}} / D_{\mathrm{tr}}=32 \mathrm{~mm} / 66 \mathrm{~mm}=0.48$. Each design parameter was determined by power, head, flow rate, rotational speed. In this study, blade number of each front and rear rotor were set as a prime number; front rotor $Z_{\mathrm{f}}=4$ and rear rotor $Z_{\mathrm{r}}=3$ in order to suppress the blade rows interaction of contra-rotating rotor. A guide vane was not set at the inlet of the front rotor because the test turbine was designed as compact as possible. The test turbine was designed so that swirling flows did not remain the downstream of the rear rotor at design flow rate. Further, a stagger angle of the rear rotor is determined on an assumption that the swirling flow the

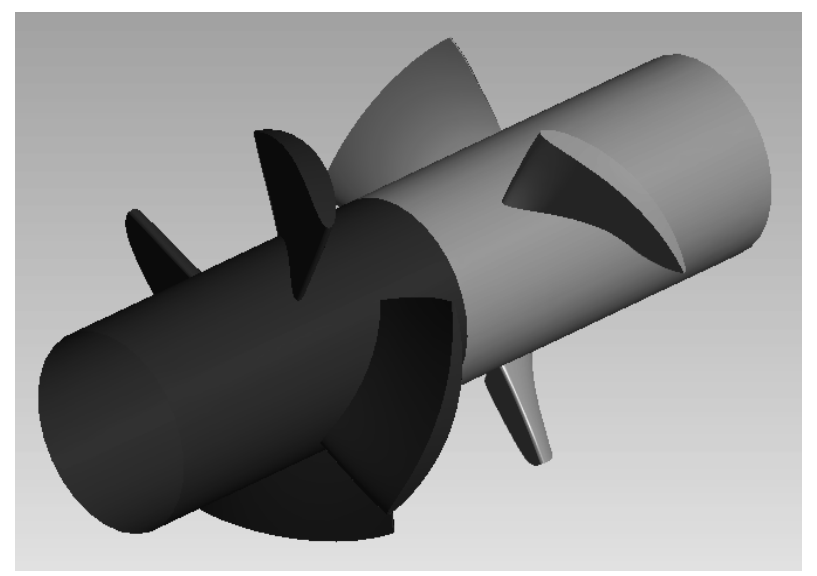

Figure 1. Test hydro turbine rotor.
Table 1. Primary dimensions of turbine rotor.

\begin{tabular}{|c|c|c|c|c|}
\hline & & Hub & Mid & Tip \\
\hline \multirow{5}{*}{$\begin{array}{l}\text { Front } \\
\text { Rotor }\end{array}$} & Diameter [mm] & 32 & 48 & 64 \\
\hline & Blade Profile & \multicolumn{3}{|c|}{ NACA6512 } \\
\hline & Blade Number & \multicolumn{3}{|c|}{4} \\
\hline & Solidity & 1.02 & 0.84 & 0.73 \\
\hline & Stagger Angle $\left[{ }^{\circ}\right]$ & 33.5 & 27.4 & 22.7 \\
\hline \multirow{4}{*}{$\begin{array}{l}\text { Rear } \\
\text { Rotor }\end{array}$} & Blade Number & & 3 & \\
\hline & Blade Profile & \multicolumn{3}{|c|}{ NACA6512 } \\
\hline & Solidity & 0.72 & 0.59 & 0.52 \\
\hline & Stagger Angle $\left[{ }^{\circ}\right]$ & 53.1 & 35.2 & 26.4 \\
\hline
\end{tabular}

downstream of front rotor, which was calculated by the design efficiency of front rotor $\left(\eta_{\mathrm{fd}}=65 \%\right)$, directly went to rear rotor.

\section{Numerical Analysis Method and Conditions}

In the numerical analysis, the commercial software ANSYS-CFX was used under the condition of $3 D$ steady flow condition. Fluid was assumed that the incompressible and isothermal water and the equation of the mass flow conservation and Reynolds Averaged Navier-Stokes equation were solved by the finite volume method. The standard wall function was utilized near the wall and the standard $k$ - $\varepsilon$ model was used as the turbulence model. The inlet region was $5 D$ upstream of the test section and the outlet region was $5 D$ downstream of it. The constant velocity and the constant pressure were given as the boundary condition at the inlet and the outlet respectively. The numerical grids used for the numerical analysis were shown in Figure 2. The numerical domains were comprised of the inlet, rotor and the outlet regions. The numerical grid elements at each region were 59,137 for the inlet region and 61,568 for the outlet region respectively. The numerical grid elements for the rotor region were 2,962,437 and 2,350,803 for the front and the rear rotors respectively. The fine grids were arranged near the tip clearance and the blade. The $\mathrm{y}^{+}$was 5 near the hub of the front and the rear rotor. The numerical analyses were performed at seven flow rate points of $90 \%, 100 \%, 120 \%$, $140 \%, 160 \%, 180 \%$ and $200 \%$ of the designed flow rate. These flow rate points were mainly set to large flow rate points because the small hydro turbine could be operated in large flow rates.

\section{Numerical Results}

Figure 3 shows the performance curves of the test turbine obtained by the numerical analysis. The horizontal 


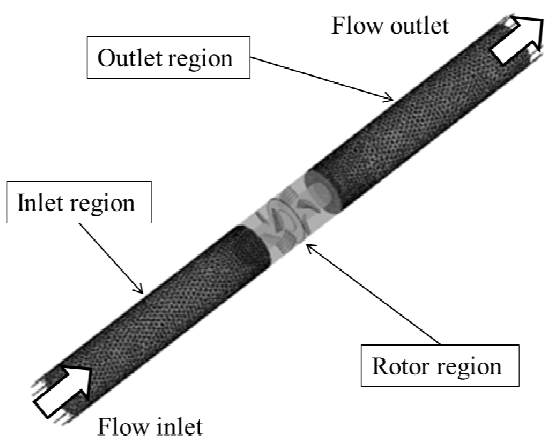

(a)

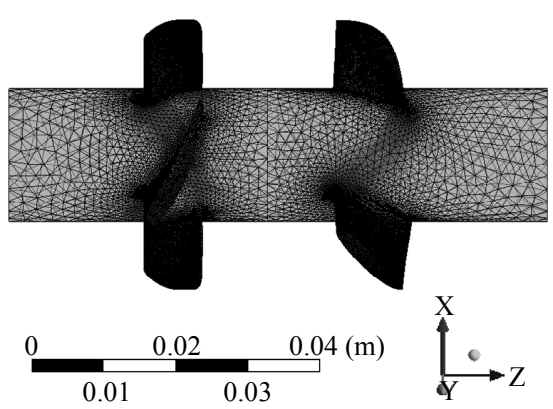

(b)

Figure 2. Numerical grids. (a) Whole regions; (b) Rotor region.

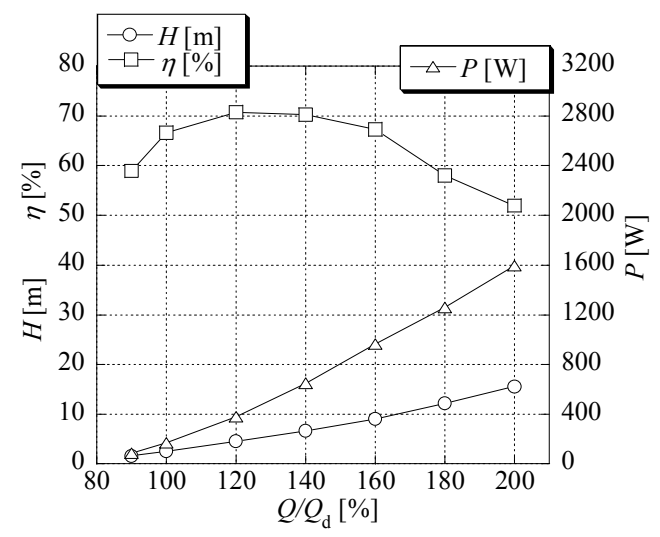

Figure 3. Performance curves.

axis shows a flow rate. First vertical axis shows a turbine head and efficiency. Second vertical axis indicates a shaft power. The rotational speed of each front and rear rotor was $N_{\mathrm{f}}=N_{\mathrm{r}}=2600 \mathrm{~min}^{-1}$. In Figure 3, the turbine head and shaft power increased with increasing a flow rate. The maximum efficiency $\eta_{\max }=70.8 \%$ was obtained at $1.2 Q_{\text {d }}$, although the contra-rotating small-sized axial flow hydro turbine was very small. Furthermore, efficiency more than $50 \%$ was obtained in relatively wide flow rates range of $0.9 Q_{\mathrm{d}}-2.0 Q_{\mathrm{d}}$. Especially around the maximum efficiency flow rates of $1.0 Q_{\mathrm{d}}-1.6 Q_{\mathrm{d}}$, the efficiency more than $65 \%$ was obtained. On the other hand, the efficiency drastically decreased at the partial flow rate point $0.9 Q_{\mathrm{d}}$ and large flow rate points $1.8 Q_{\mathrm{d}}$ and $2.0 Q_{\mathrm{d}}$.
Figure 4 shows total pressure efficiency curves of each front and rear rotor obtained by the numerical analysis. The total pressure efficiency of the front rotor was calculated from the ratio of the shaft power of the front to the input which was obtained by the multiplication of the flow rate and the mass flow averaged total pressure difference between the section at the $2 D$ upstream of the test section and the interface between the front and the rear rotors. The axial position of the interface was midsection between the front and the rear rotors; the axial section $15.5 \mathrm{~mm}$ downstream from the trailing edge of the front rotor hub. Further, the total pressure efficiency of the rear rotor was also calculated from the ratio of the shaft power of the rear rotor to the input which was obtained by the flow rate and the mass flow averaged total pressure difference between the $2 D$ downstream section of the test section and the interface between the front and the rear rotors. In Figure 4, the total pressure efficiency of the front rotor was slightly affected by a flow rate change, however, the total pressure efficiency of the rear rotor drastically decreased in partial and large flow rates. Therefore, we investigated the internal flow at the large flow rate $1.8 Q_{\mathrm{d}}$ in order to consider a cause of performance deterioration in the large flow rate range from the numerical results.

Figures 5(a) and (b) show the relative velocity vectors around the blade at the radial mid position $\left(r / r_{\mathrm{c}}=0.73\right)$. The flow rate in Figure 5 is $1.8 Q_{\mathrm{d}}, r$ is the radial position and $r_{\mathrm{c}}$ is radius at the casing. The water around the front rotor flowed along the blade at $r / r_{\mathrm{c}}=0.73$ in Figure 5(a), although the flow rate was much larger than the designed flow rate $Q_{\text {d. }}$. A large separation region could not be observed on the blade surface of the front rotor, however, a slight separation occurred near the leading edge of the front rotor on the suction surface. On the other hand, it was observed from Figure 5(b) that a large separation region occurred on the suction surface of the rear rotor. Total pressure distribution around the front and the rear

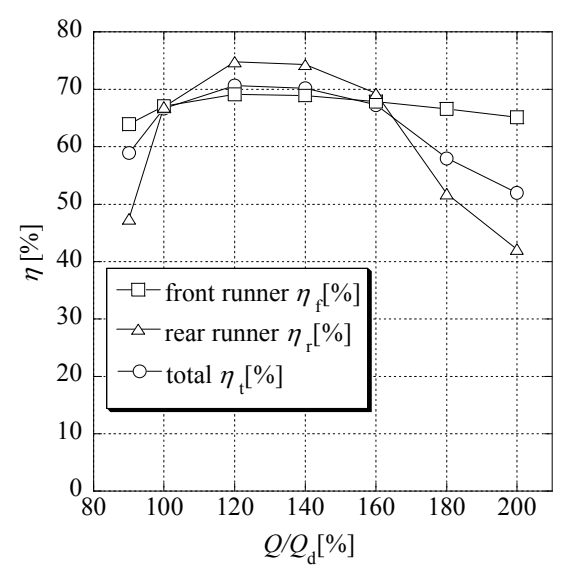

Figure 4. Total pressure efficiency curves of each front and rear rotor. 
rotors at $r / r_{\mathrm{c}}=0.73$ at $1.8 Q_{\mathrm{d}}$ are shown in Figures 6(a) and (b) respectively. There was not a region, where a total pressure has drastically decreased in the front rotor. However, a total pressure decreased drastically in the separation region of the rear rotor shown in Figure 5(b). This large loss was caused by the separation in the suction surface. Then, the flow condition of the rear rotor around flow rates, where the total pressure decreased significantly, was focused. Figures 7(a) and (b) showed total pressure distributions of the rear rotor at $r / r_{\mathrm{c}}=0.73$ at $1.6 Q_{\mathrm{d}}$ and $2.0 Q_{\mathrm{d}}$ respectively. A low total pressure region was small on the suction surface of the rear rotor at flow rate $1.6 Q_{\mathrm{d}}$ in Figure 7(a), however, there was a large low total pressure region on the suction surface of the rear rotor in large flow rates region over $1.8 Q_{\mathrm{d}}$. It was considered that the increase of the low total pressure region associated with the decrease of efficiency of the rear rotor in flow rates region over $1.8 Q_{\mathrm{d}}$ confirmed in Figure 4. The efficiency of the rear rotor at $1.6 Q_{\mathrm{d}}$ declined by about $5 \%$ compared to the maximum efficiency, however, at $1.8 Q_{\mathrm{d}}$ the efficiency decreased significantly by approximately $25 \%$ compared to the maximum efficiency.

The test turbine was designed under the condition that the blade loads of the front and the rear rotors were the same and the circumferential component of absolute velocity on the downstream of rear rotor did not exist at the designed flow rate. Therefore, a variation of circumferential velocity distributions the downstream of rear rotor according to the change of flow rates was focused. The circumferential velocity distributions in radial direction at $5 \mathrm{~mm}$ downstream of the trailing edge of the rear rotor were shown in Figure 8. The circumferential velocity is a positive in the rotational direction of the front rotor. The circumferential velocity the downstream of the rear rotor was almost zero from a partial rate to large flow rate $1.6 Q_{\mathrm{d}}$. It was found that exhaust loss was small in these flow rates range, where a good performance obtained.

On the other hand, the circumferential velocity remained the downstream of the rear rotor at large flow

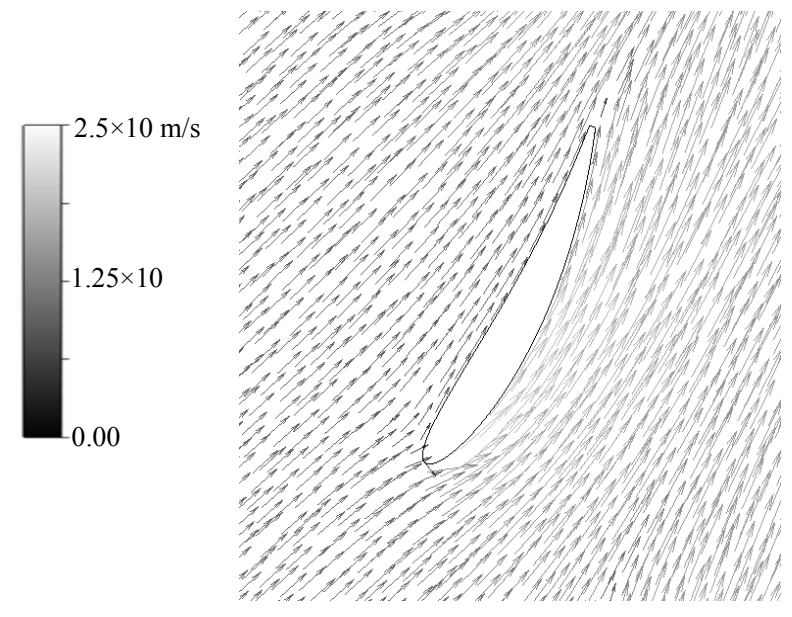

(a)

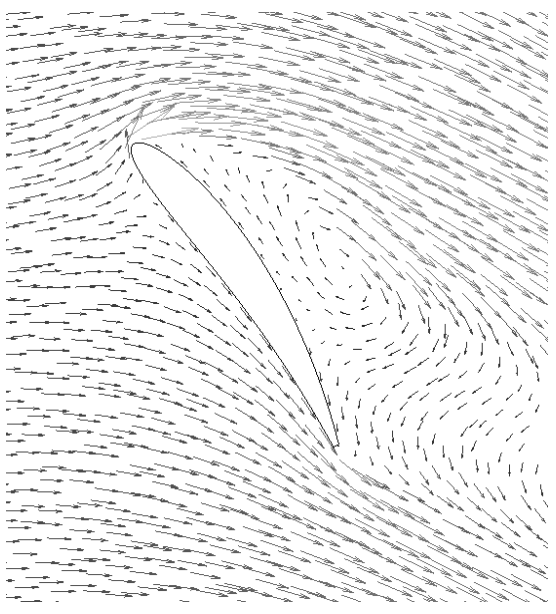

(b)

Figure 5. Relative velocity vectors at $r / r_{\mathrm{c}}=0.73\left(1.8 Q_{\mathrm{d}}\right)$. (a) Front rotor; (b) Rear rotor.

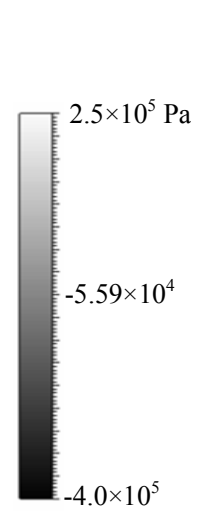

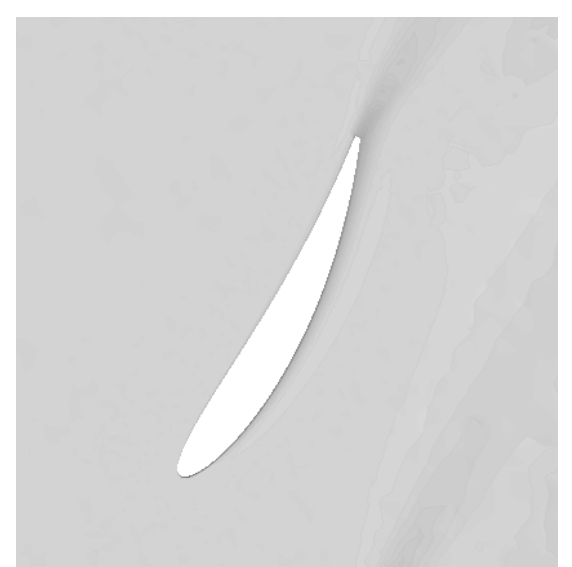

(a)

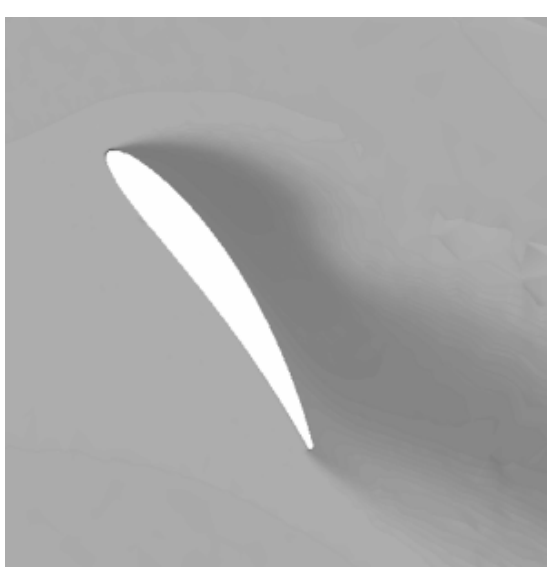

(b)

Figure 6. Total pressure distribution at $r / r_{\mathrm{c}}=0.73\left(1.8 Q_{\mathrm{d}}\right)$. (a) Front rotor; (b) Rear rotor. 


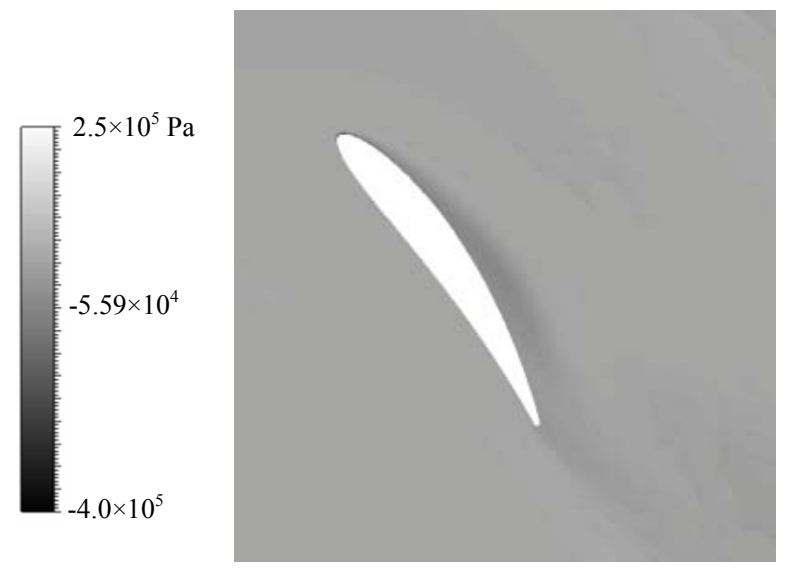

(a)

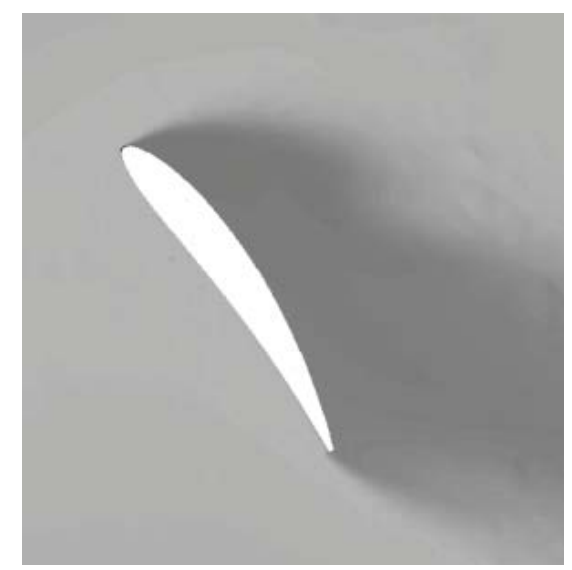

(b)

Figure 7. Total pressure distribution of the rear rotor at $r / r_{c}=0.73$. (a) $1.6 Q_{d}$; (b) $2.0 Q_{d}$.

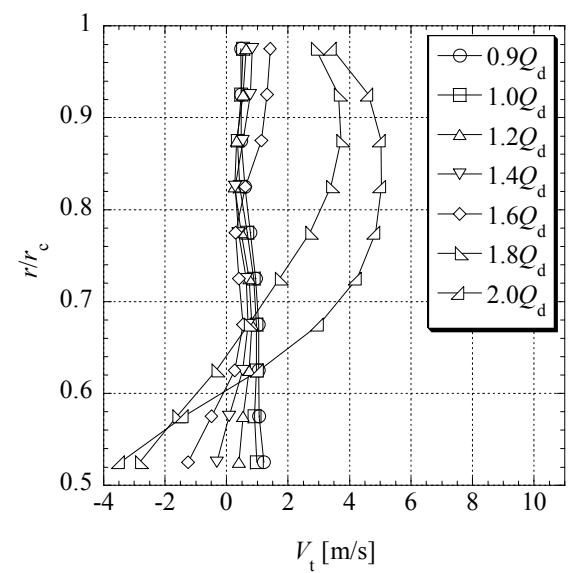

Figure 8. Circumferential velocity distributions at outlet of the rear rotor.

rate points $1.8 Q_{\mathrm{d}}$ and $2.0 Q_{\mathrm{d}}$ and the circumferential velocity from the downstream of the front rotor could hardly been recovered by the rear rotor. It was considered that the total pressure and exhaust loss have a huge influence on the performance deterioration at large flow rate points $1.8 Q_{\mathrm{d}}$ and $2.0 Q_{\mathrm{d}}$. Therefore, the contra-rotating small-sized axial flow hydro turbine which had an advantage of the independent rotational speed control of the front and the rear rotors, was effective for improving these losses. Especially, control of the rotational speed of the rear rotor could make high performance operation of the contra-rotating small-sized axial flow hydro turbine in wide flow rates range.

\section{Conclusions}

Contra-rotating small-sized axial flow hydro turbine with the diameter less than $70 \mathrm{~mm}$ was designed and the performance and internal flow were investigated with the numerical flow analysis. The following conclusions could be obtained.
1) It was found that the maximum efficiency $\eta_{\max }=$ $70.8 \%$ was obtained, although the contra-rotating smallsized axial flow hydro turbine was very small. Furthermore, efficiency more than $50 \%$ was obtained in relatively wide flow rates range of $0.9 Q_{\mathrm{d}}-2.0 Q_{\mathrm{d}}$;

2) Efficiency of the front rotor showed comparatively high values in $0.9 Q_{\mathrm{d}}-2.0 Q_{\mathrm{d}}$. However, efficiency of the rear rotor drastically decreased at partial flow rate point $0.9 Q_{\mathrm{d}}$ and large flow rate points $1.8 Q_{\mathrm{d}}$ and $2.0 Q_{\mathrm{d}}$;

3) A separation occurred on the suction surface of the rear rotor at large flow rate points $1.8 Q_{\mathrm{d}}$ and $2.0 Q_{\mathrm{d}}$, and total pressure drastically decreased on this separation area. In addition, the circumferential velocity remained the downstream of the rear rotor at these flow rate points, and the exhaust loss occurred.

\section{Acknowledgements}

This research was supported by the Awa Bank Science and Culture Foundation, Adaptable and Seamless Technology Transfer Program through Target-driven R\&D from JST, the Grant-in-Aid for Young Scientists (B) under Grant No.24760138 from Japan Society for the Promotion of Science, TEPCO Memorial Foundation and Hatakeyama Culture Foundation.

\section{REFERENCES}

[1] A. Furukawa, K. Okuma and A. Tagaki, "Basic Study of Low Head Water Power Utilization by Using DarrieusType Turbine," Transactions on JSME, Vol. 64, No. 624, 1998, pp. 2534-2540. (in Japanese) doi:10.1299/kikaib.64.2534

[2] T. Kanemoto, A. Inagaki, H. Misumi and H. Kinoshita, "Development of Gyro-Type Hydraulic Turbine Suitable for Shallow Stream (1st Report, Rotor Works and Hydroelectric Power Generation)," Transactions on JSME, Vol. 70, No. 690, 2004, pp. 413-418. (in Japanese)

[3] J. Matsui, "Internal Flow and Performance of the Spiral 
Water Turbine," Turbomachinery, Vol. 38, No. 6, 2010, pp. 358-364. (in Japanese)

[4] T. Ikeda, S. Iio and K. Tatsuno, "Performance of NanoHydraulic Turbine Utilizing Waterfalls," Renewable Energy, Vol. 35, No. 1, 2010, pp. 293-300. doi:10.1016/j.renene.2009.07.004

[5] M. Nakajima, S. Iio and T. Ikeda, "Performance of Savonius Rotor for Environmentally Friendly Hydraulic Turbine," Journal of Fluid Science and Technology, Vol. 3, No. 3, 2008, pp. 420-429.

\section{Nomenclature}

$D \quad$ diameter $(\mathrm{mm})$

$P \quad$ shaft power (W)

$N \quad$ rotational speed $\left(\mathrm{min}^{-1}\right)$

$H \quad$ turbine head $(\mathrm{m})$

$Q \quad$ flow rate $\left(\mathrm{m}^{3} / \mathrm{s}\right)$

$r \quad$ radial position $(\mathrm{mm})$

$r_{\mathrm{c}} \quad$ radius at the casing $(\mathrm{mm})$

$V_{\mathrm{t}} \quad$ circumferential velocity $(\mathrm{m} / \mathrm{s})$

$Z \quad$ number of the blade doi:10.1299/jfst. 3.420

[6] S. Iio, F. Uchiyama, C. Sonoda and T. Ikeda, "Performance Improvement of Savonius Hydraulic Turbine by Using a Shield Plate," Turbomachinery, Vol. 37, No. 12, 2009, pp. 743-748. (in Japanese)

[7] S. Iio, S. Oike, E. Sato and T. Ikeda, "Failure Events in the Field Test of Environmentally Friendly Nano-Hydraulic Turbines," Turbomachinery, Vol. 39, No. 3, 2011, pp. 162-168. (in Japanese)

\section{Greekletter}

$\eta \quad$ efficiency

\section{Subscripts}

$\begin{array}{ll}\mathrm{h} & \text { hub } \\ \mathrm{t} & \text { tip } \\ \mathrm{f} & \text { front rotor } \\ \mathrm{r} & \text { rear rotor } \\ \mathrm{d} & \text { designed point }\end{array}$

